\title{
Materials Science and Engineering Study Commences
}

\author{
Five Panels Established; Objectives Identified
}

The May/June 1985 issue of the MRS BULLETIN summarized discussion held during the "Forum of Materials Science and Engineering" at the National Academy of Science in Washington, DC, in March. The forum was held to enable the materials community to offer advice on the scope and emphasis of a proposed new study of materials science and engineering to be conducted by the National Research Council.

The purpose of the proposed Materials Science and Engineering (MSE) Study was to review the status of materials science and engineering, further unify the field, provide a plan for continued oversight of materials research issues, and develop a detailed organizational structure to carry out identified $R \& D$ policies on the national level.

That study has now begun under the direction of cochairmen Praveen Chaudhari, vice president of science at IBM Corporation, and Merton Flemings, professor of materials science at Massachusetts Institute of Technology. A chairman and two vice chairmen for each of five panels are currently being selected. A meeting was held December 19,1985 in Washington, DC, to delineate goals and objectives of the study. Following is a list of each panel and some of its anticipated activities. These are pre- liminary outlines of their activities and are expected to be modified as the panel chairmen, vice chairmen, and members are named.

Panel 1: Materials Research Opportunities and Needs in MSE

The panel will attempt to identify areas of national importance involving materials that affect human welfare and national security. It will establish yardsticks for evaluating opportunities and needs, and assess generic areas of science and engineering.

Panel 2: Exploitation of MSE and Technology for National Welfare

The panel will consider the interaction of science and technology to identify current means by which technology needs to reach the scientific community; current means by which scientific ideas are translated to technology; current methods in materials science and engineering for translating concepts in to effective and reliable processes and products; and prospects for future development in each of these areas.

Panel 3: International Cooperation and Competition The panel will identify the major national contributors to materials science and engineering in terms of facilities, resources, and manufacturing, and their relative quality of contributions, facilities and plans. It will also identify the major contributors' national goals in materials science and engineering and explore areas of cooperation and steps in materials science and engineering needed to improve U.S. industrial competitiveness.

Panel 4: Research Resources in MSE

The panel will consider existing resources such as manpower, facilities and equipment at universities, national laboratories, and industrial laboratories. It will also identify future needs.

Panel 5: Education in MSE

The panel will identify existing human resources for education in materials science and engineering and explore future direction of education in materials science and engineering, including education in and out of materials science departments. Needs and opportunities for increasing interdisciplinary research in materials science and engineering education, and needs and opportunities in lifelong education will also be addressed.

\section{Specific Objectives Forthcoming}

The descriptions provided above are based on strawman outlines being provided to panel chairmen to serve as points of reference. As the panels are formed, the specific goals of each panel will be established. Look for additional information in upcoming issues of the BULLETIN.

MIRIS

\section{ANNUAL FORUM OF THE SOLID STATE SCIENCES COMMITTEE March 10-11, 1986 Auditorium of the National Academy of Sciences Washington, DC}

The purpose of the Forum is to bring together the materials science community with leading national policy and decision makers.

\author{
For further information, contact Donald Shapero, \\ telephone (202) 334-3520.
}

